\title{
Current and Future Contributing Factors and Trends in the Usage of IT Cloud Computing in Manufacturing and Service Sectors
}

\author{
Vipin K. Agrawal ${ }^{1}$, Vijay K. Agrawal ${ }^{2}$, Ngan N. Chau ${ }^{3}$, Matthew Miller ${ }^{4}$, Sherri Harms ${ }^{5}$ \\ ${ }^{1}$ University of Texas at San Antonio, Texas, USA \\ ${ }^{2-5}$ University of Nebraska at Kearney, Nebraska, USA
}

\begin{abstract}
Cloud computing provides organisations with the ability to quickly change infrastructure, provider and service levels. The study looks at factors affecting the usage of cloud computing by organisations in the manufacturing and service sectors in the United States. Extrinsic motivation was found to be a significant factor for change in cloud computing budget allocation in manufacturing, whereas intrinsic motivation was a significant factor in the service sector. The study also shows that organisations' future budgets include internal and external sources to fulfil their IT needs.
\end{abstract}

Keywords - Cloud Computing; IT Management and Strategy; Optimum Investment on IT Resources; Predictive Models.

\section{INTRODUCTION}

Cloud computing usage has increased rapidly over the past 20 years. At the turn of the millennium, computer hardware was beginning to reach the Gigahertz range, and now modern consumer processors have 64 processors per die and GPUs have up to 5000 cores per graphics card [1]. The cost of hardware has dropped significantly due to the advances in computer chip design and the advancements in the photolithography. Cloud computing has been projected to grow at an annual growth rate of $12.6 \%$ and go from $\$ 184$ billion in 2018 to $\$ 331$ billion in 2022 [2]. According to Gartner, more than $\$ 1.3$ billion will shift from traditional computing to cloud computing [3]. The investment in cloud computing is a top three priority for investment by more than 1 in 3 companies [4].

The use of cloud computing has shifted the burden of developing in-house IT infrastructure requirements such as keeping up with computing trends, and purchasing, managing and maintaining computer hardware. Benefits of adopting cloud computing include reduction in initial expense, flexibility in deployment, and dynamic expansion of cloud resources. Organisations can focus on selecting the cloud providers that meet their needs as those needs arise. This shift provides flexibility for organisations but comes at a different type of cost. Organisations must focus on cloud computing aspects of data portability, quality of service, security, integration, and service contracts in the fluid cloud market [5]. For specific organisations, these risks are too high to rely on cloud providers. Examples include the use of drones in the military [6], the restriction on the use of fitness devices by the Pentagon
[7] and the use of Kaspersky Antivirus software by the U.S. government [8].

\section{LITERATURE REVIEW}

The identification of the factors used when making forward looking decisions on technological investments is critical in predicting where the cloud computing industry will be heading in the near future. This literature review will provide an overview of the current benefits, challenges and risks involved in migrating computing infrastructure to cloud provided platforms.

\section{A. Cloud Computing}

Cloud computing is a service that provides organisations and individuals with a hosted computing, networking and information technology. Cloud computing providers offer a variety of different services to meet the needs of their consumers. Cloud computing providers reduce the amount of management and control that is required by their consumers. These services allow consumers to focus on their core competencies, instead of concerning themselves with the details of computer and networking infrastructure. There are three major areas of service that can be provided by cloud providers: Software as a Service (SaaS), Platform as a Service (PaaS) and Infrastructure as a Service (IaaS) [9]. SaaS provides an organisation with access, use and updates to software systems. Examples of SaaS services include Microsoft Office 365, Sales Force and DropBox [10]. PaaS provides a platform that allows consumers to create, test, run and manage applications. Examples of PaaS services include Microsoft Azure and Amazon Web Services (AWS) [11]. IaaS provides the infrastructure (-services and networking equipment) but does not perform management of the operating system and system software. Examples of IaaS include DigitalOcean, Linode and Rackspace [12]. NIST defines the nature of cloud computing characteristics: On-demand, broadband access, the pooling of resources, rapid elasticity and measured service [9].

\section{B. Advantages of Cloud Computing}

The growth of cloud computing over the past 20 years and the projected future growth clearly show that there are significant advantages to using cloud computing. The transition 
to cloud computing has many benefits, which are classified in four categories [13].

\section{Extrinsic Motivation:}

Research has shown that the ability to use the resources that are the state of the art and accessible $24 / 7$ is a major benefit of cloud computing to many organisations [14]. The reduced cost for services that can be paid for as they are used rather than purchasing hardware upfront [15], [16] is another benefit.

The standardisation of protocols, services and APIs has allowed the market to mature rather than fragmentize. Most cloud computing providers support standard technologies such as web services (http/https) for access and management [17] Support for standard virtualization technologies like Open Virtualization Format (OVF) [18] has accelerated the adoption of PaaS by organisations [19].

The ability to develop, deploy and run applications without having to manage the location, configuration and security has simplified the process for organisations [20]. In fact, many of these cloud services (e.g., Dropbox, Zoom and YouTube) are ready to be deployed by any corporation with very little technical management required [21]. The ability of organisations to focus on management of services rather than technical requirements allows them to consolidate their resources and staff. Additionally, the readiness to deploy services can make organisations adapt to changes in the market very quickly. If a large provider like Dropbox does not deploy a new feature that a competitor possesses, they may lose market share. This provides a business market, where there is rapid change and the adaption of cloud solutions. Managers will be influenced by the promise of technology and they will embrace cloud computing, ignoring the associated risks. Diffusion theory [22] also suggests that relative advantages and observability of benefits accrued by early adopters of cloud computing provide the impetus for managers to adopt similar strategies. It is therefore highly likely that the perceived benefits of cloud computing will overpower any perceived associated risks and will provide extrinsic motivation to them in order to adopt higher usage of cloud computing.

Hypothesis H1: The "Extrinsic Motivation" will increase the usage of cloud computing in the next five years, for both the manufacturing and service sectors.

\section{Intrinsic Motivation:}

The ability of organisations to flexibly deploy technology allows them to change at a rapid pace. Organisations rate flexibility, agility and speed as some of the most important technology issues [23]. Cloud providers offer services that are completely automated, which include the deployment of technology, monitoring of use and the billing of services used. Cloud computing allows inexpensive devices to drastically change functionality without any significant capital investment by an organisation. Organisations also have a reduced capital investment and reduced real estate [24]. The shared nature of cloud computing allows computing resources to be efficiently utilised, reducing energy usage and, in turn, helps reduce the carbon footprint of technology [25]. It is therefore highly likely that the perceived benefits of cloud computing such as flexibility, adaptability, agility, scalability, enhancing the mobility, collaboration and productivity of their workforce will provide intrinsic motivation to the managers in order to adopt higher usage of cloud computing.

Hypothesis H2: The "Intrinsic Motivation" will increase the usage of cloud computing in the next five years, both in the case of manufacturing and service sectors.

\section{Perceived Risks (Disadvantages of Cloud Computing)}

The use of cloud computing introduces many new risks to organisations. Some examples of perceived risks include resource isolation failure, malicious attacks on the cloud provider and the breaching of data from the cloud provider [26]. These risks can be categorised into four different categories: legal, technical, organisational and operational [24].

Legal. Many industries are regulated by state, federal, and international entities. The use of cloud computing then changes the legal requirements that must be met [24]. For example, if an organisation provides a website that stores Health Care data, then the Health Insurance Portability \& Accountability Act (HIPPA) [27] provides restrictions on who can access the data. If an organisation provides digital services to customers that reside in the European Union, then that organisation must adhere to the General Data Protection Regulation (GDPR) [28]. These risks change the risk calculation performed by an organisation. Organisations will also try and purchase cyber insurance to mitigate these risks, by understanding the terms through which cyber insurance is in a constant state of flux. Additionally, the cost of cyber insurance can be a hidden risk, depending on the annual cost of the insurance as well as how much the insurance fails to pay out during an incident [29].

Technical. When organisations switch to using cloud computing, they lose the ability to control some features of the cloud environment. This may include the ability to control updates and audit systems [24]. If organisations choose to migrate current services to the cloud, they may lose technical expertise in such areas as cybersecurity, data management and infrastructure management.

Organisational risks associated with cloud computing include the loss of professional IT specialists, who have an insight into IT. A business may lose the organisational workforce to migrate from one cloud service to another and maintain continuity with business goals. Reliance on cloud hosted services to provide business operations increases the risk that a disaster (natural or manmade) occurs. The occurrence of a natural disaster in a region of the country may cause the loss of network connectivity and thus the loss of cloud services. Additionally, there can be a loss of connectivity to a cloud service. The depletion of IT staff can make that loss more impactful, costly and lengthy. For example, when the city of Baltimore was hit by a ransomware attack, the understaffed IT department worked around the clock to reset stolen credentials [30]. The attack cost the city of Baltimore more than $\$ 10$ 
million to clean up and more than $\$ 8$ million in lost revenue. The IT officer of Baltimore had warned that the IT department was understaffed, but the council ignored the warning [31].

Operational. Service Level Agreements (SLA) between an organisation and a cloud provider provide a contract of how the service should be provided to the organisation. Without proper levels of service, a cloud service may not meet the needs that an organisation is accustomed to with the traditional IT infrastructure. Additionally, if the cloud provider does not provide a level of service that meets the need of the organisation, then the business needs may not be met. The cloud causes an operational risk when the cloud provider is unavailable, whether it is due to a cloud failure or a local connectivity issue. The ability to transfer between cloud providers can also be a risk to business [32]. The risk of cloud vendor lock-in can pose a great challenge to organisations that want to adopt cloud technologies, as the promise of cloud computing is flexibility.

Risk adverse organisations may choose to avoid risks associated with the investment in cloud computing. This choice may have precedence over low-level managers' desire to implement such solutions. Therefore, loss aversion is more likely to sway their decision to cloud computing usage.

Hypothesis H3: The "Perceived Risks" will decrease the usage of cloud computing in the next five years, both in the case of manufacturing and service sectors.

\section{Resource Limitation}

Cloud computing allows an organisation to move capital investment to the core of the business model from IT personal and technical infrastructure. IT has grown from $5 \%$ of capital expenditures in the 1960 s to almost $50 \%$ in the 1990s [33]. The rise of the Internet in the late 1990s transformed business and commercial infrastructure in a way that had not been seen since the industrial revolution [34]. Cloud computing has allowed organisations to reduce capital expenditures and become more flexible and agile. Organisations can use capital to invest in IT personnel with different skill sets or to prioritise new projects [35]. For example, an organisation may choose to invest in the management of multiple cloud vendors. This investment requires the organisation to develop the core competency to manage vendors and service level agreements [36]. The line between off-the-shelf software and cloud computing has also blurred, as software publishers provide cloud versions of their software. Microsoft has pushed many services, such as Microsoft Office, Windows and Xbox, to online offerings, such as Office 365, Azure and Xbox Live [37]. The new flexibility allows organisations to deploy services more rapidly than with traditional models, which provides perceived benefits, such as increased stock evaluations and faster market deployment [38]. Many organisations will choose to purchase software rather than to build the software in-house. Current organisational needs can be met with the integrated, large-scale application software. Associated risks in developing such software inhouse are significantly high, as the risk of going over budget and under delivering will also steer organisations to purchase cloud computing solutions [39]. Therefore, the resource constraints will likely to be a leading factor in the decision made by managers in higher usage of cloud computing solutions.

Hypothesis H4: The "Resource Constraints" will increase the usage of cloud computing in the next five years, both in the case of manufacturing and service sectors.

\section{METHODOLOGY}

This study is an extension of [13], which was exploratory and preliminary in nature. The current study is an in-depth analysis and categorization with comparison between manufacturing and service sectors. The study looks at these sectors independently to discover which attributes are important to decision makers in each sector in their determination of cloud computing utilisation and budget allocation. While [13] introduces understanding the factors that are important to the overall usage adoption decision of this information technology delivery model and the implications for organizations in the United States, this paper provides an in-depth analysis of cloud computing usage in the manufacturing and service sectors in the United States. Further, it evaluates the contributing factors that drive the changes in planned IT investment in cloud computing, as well as the planned changes in IT budget allocations.

Following [40], the analysis was performed in three stages, detailed in [13]. At the first stage, questionnaire items were finalised using a face validity assessment process, which generated 29 questions (D1-D29) corresponding to the factors that decision makers perceived to be important for the adoption of cloud computing.

\section{A. Stage 1. Face Validity}

Face validity of each item was assessed in three steps. First, a list of items was initially developed for the questionnaire, based on the authors' expertise in the Management, MIS and IT disciplines. These items operationalized the variables of interest. The authors reached preliminary consensus on the question phrasings and then independently assessed them. These assessments were compared for inter-rater concordance, and questions rephrased as needed. Finally, IT executives from four different firms reviewed question phrasings and the time required to respond.

A Delphi-like technique was used to finalize the phrasing of measured items as explained in [13]. In the Delphi method, experts were consulted across multiple rounds to anonymously answer the questions under consideration. After each round, results were reviewed, and questions revised based on the information gained. Multiple rounds were conducted until either consensus was achieved or no additional perspectives were obtained. For this study and the [13] study, classification of questions into variables was conducted using a panel of seven industry experts from various backgrounds.

\section{B. Stage 2. Data Collection and Construct Validity}

During the second stage, the survey was given, and items ranked based on their average respondent scores. Following the guidelines suggested by [41], [42], a six-page questionnaire was 
administered as described in [13]. To mitigate non-responses, no open-ended questions were utilised.

The targeted sample was IT professionals with some responsibility for making IT management decisions (executive, director, first line management, middle management) from manufacturing and service sectors in the United States. The sampling frame was a fee-based online panel of IT professionals offered by Qualtrics, a leading online survey research platform. Study [43] indicated that such online panels were of lower cost, provided faster responses, and had the ability to obtain a targeted sample of people who were scarce in the general population [13].

Those who chose to participate were first asked to indicate the industry they were employed in. To ensure adequate representation of each industry type, target quotas of 80 service sector responses and 70 manufacturing sector responses were established. The service sector industry type had an additional target quota of 40 respondents in the Computer Software industry sector and 40 respondents for other service industry sectors. Once a quota was reached, Qualtrics deactivated the links given in the invitation to participate for that particular sector. The deactivated links were based upon the industry each respondent's panel profile indicated they were employed in. Respondents who began a survey before the link was deactivated were allowed to finish the survey. Out of the initial sample size of 153, the total of 148 usable responses were received, resulting in a $97 \%$ response rate [13].

The questionnaire also asked the participant to provide the percentage of the current IT budget (item C1) and expected IT budget in five years (item C2) allocations to buying and management of different types of IT services: 1. In-House; 2. Outsourcing/Offshoring; 3. Cloud Computing; and 4. Application Service Provider (ASP). These questions give an insight into the future growth planned for cloud computing relative to other planned IT investments for the manufacturing and service sectors. The change in expected IT budget allocation for cloud computing was employed as a dependent variable in the statistical analysis of the four hypotheses.

\section{Profile of Responding Firms and Respondents}

In the manufacturing sector, $67.6 \%$ of the 71 respondents were from manufacturing and $23.9 \%$ from computer hardware, while in the service sector, 77 respondents included 38 from computer software and 19 from technology, making that industry representation relatively higher $(49.4 \%+24.7 \%=$ $74.1 \%$ ) compared to other industries. Respondents in the manufacturing sector were distributed fairly in good proportion among the organisations with sales revenue between $\$ 5$ million and $\$ 1$ billion, while in the service sector the fair distribution was between sales revenue of $\$ 5$ million to $\$ 2$ billion.

The perception about issues related to IT seems to have a fair representation based on the respondent's profile in the organisation. The largest proportion of respondents, both in the manufacturing and service sectors, was from senior level management. More than $70 \%$ of the respondents in manufacturing, as well as in the service sector, were from top management, i.e., first line management and above (directors and executives). Furthermore, more than $75 \%$ of the respondents (either in the manufacturing or service sector) were from information systems departments, as intended for this survey research. The remaining respondents were directly associated with the information systems department. In most of the respondents' organisations, the full-time information systems' employees were 100 or higher having IT department's budget more than $\$ 10$ million.

\section{Suitability of Respondent Data}

\section{TABLE I}

MEASUREMENT OF SAMPLing ADEQUACy USING KMO AND BARTLETT'S TEST OF SPHERICITY

\begin{tabular}{|c|c|c|}
\hline \multicolumn{2}{|c|}{ Kaiser-Meyer-Olkin Measure of Sampling Adequacy } & $\mathbf{0 . 9 2 9}$ \\
\hline Bartlett's Test of Sphericity & Approx. Chi-Square & 1537.033 \\
\cline { 2 - 3 } & $d f$ & 78 \\
\cline { 2 - 3 } & Sig. & 0.000 \\
\hline
\end{tabular}

Prior to factor extraction, the suitability of respondent data for Step 3 (focusing on a factor analysis) was assessed. The test used included Kaiser-Meyer-Olkin (KMO) Measure of Sampling Accuracy [44], [45] Correlation Analysis [46], and Bartlett's Test of Sphericity [47]. SPSS version 23.0 was used for all data analysis conducted in this study. The KMO index is recommended when the cases to a variable ratio are less than 1:5. The KMO index ranges from 0 to 1 , with 0.5 considered suitable for a factor analysis [48], [49]. When analysing the correlations of the items, only items with a correlation of 0.4 and above were retained for a factor analysis [46]. All items were correlated with all other items at the level greater than 0.4 with 0.406 being the lowest correlation between any two items. The Bartlett's Test of Sphericity should be significant $(p<0.05)$ for a factor analysis to be suitable [48], [49]. For the data used in this study, the KMO index was 0.929 and Bartlett's Test of Sphericity had a significance level $p=0.000$ (Table I); therefore, the respondents' data were suitable for a factor analysis.

\section{Stage 3. Factor Analysis}

Stage 3 was divided into three parts: (A) exploratory factor analysis using a principal component factor analysis with Varimax rotation, followed by a confirmatory factor analysis to group the measured items by the constructs (or factors) that contributed to the adoption decision of cloud computing; (B) exploration of data clusters/classifications; and (C) development of the regression model to test the hypotheses.

\section{Stage 3. Part A. Exploratory Factor Analysis}

Exploratory factor analysis was used to classify survey items into four factors: Extrinsic Motivation, Intrinsic Motivation, Perceived Risks, and Resource Constraints, to eliminate items with low factor loadings. The number of factors were selected based on [50]. As described in [13], a principle component analysis extraction method with varimax rotation was used, first considering the number of factors contributing to cloud 
computing adoption/usage that would exceed 0.6 variance explained. Items with loadings less than 0.6 were dropped [51].

TABLE II

FACTOR ANALYSIS - LOADING AND VARIANCE IN THE FOUR-FACTOR MODEL (RESCALED)

\begin{tabular}{|c|c|c|c|c|}
\hline \multirow{2}{*}{$\begin{array}{c}\text { Item Loadings under the Four-Factor } \\
\text { Model }\end{array}$} & \multicolumn{4}{|c|}{ Rescaled Component } \\
\hline & F1 & F2 & F3 & F4 \\
\hline \multicolumn{5}{|l|}{ Extrinsic Motivation } \\
\hline $\begin{array}{l}\text { D3 Access to world-class capabilities, } \\
\text { including } 24 / 7 \text { services }\end{array}$ & 0.692 & 0.341 & 0.225 & 0.0351 \\
\hline $\begin{array}{l}\text { D24 Maturity and standardisation of } \\
\text { technology }\end{array}$ & 0.680 & 0.216 & 0.339 & 0.357 \\
\hline $\begin{array}{l}\text { D27 Simplifying overall IT environment and } \\
\text { data centre or IT consolidation }\end{array}$ & 0.765 & 0.218 & 0.355 & 0.138 \\
\hline D28 Rapid change in business process cycle & 0.811 & 0.279 & 0.255 & 0.199 \\
\hline D29 Shrinkage in system life cycle & 0.677 & 0.504 & 0.160 & 0.291 \\
\hline \multicolumn{5}{|l|}{ Intrinsic Motivation } \\
\hline $\begin{array}{l}\text { D7 Firms become more flexible, dynamic, } \\
\text { adaptable, agile, and have scalability }\end{array}$ & 0.537 & 0.203 & 0.678 & 0.075 \\
\hline $\begin{array}{l}\text { D20 Saving energy and reducing carbon } \\
\text { footprint (Greener IT) }\end{array}$ & 0.188 & 0.163 & 0.777 & 0.401 \\
\hline $\begin{array}{l}\text { D23 Improving mobility, collaboration, and } \\
\text { productivity }\end{array}$ & 0.412 & 0.310 & 0.666 & 0.132 \\
\hline \multicolumn{5}{|l|}{ Perceived Risks } \\
\hline $\begin{array}{l}\text { D15 Higher resistance from employees - job } \\
\text { loss, lower employee morale, potential for } \\
\text { poor quality }\end{array}$ & 0.252 & 0.749 & 0.379 & 0.267 \\
\hline D16 Potential breach of security & 0.379 & 0.847 & 0.048 & 0.141 \\
\hline D18 Risks during transition & 0.216 & 0.720 & 0.353 & 0.312 \\
\hline \multicolumn{5}{|l|}{ Resource Constraint } \\
\hline D10 Lack of internal resources & 0.200 & 0.212 & 0.251 & 0.859 \\
\hline D12 Cost of failure & 0.410 & 0.341 & 0.154 & 0.739 \\
\hline
\end{tabular}

Table II shows the four-factor model for factor loadings of 13 out of the 29 measured items after this process, with important factorings in bold. We used lavaan package in $\mathrm{R}$ to fit the model. The CFA supported the model overall. In particular, a value above 0.90 for the Comparative Fit Index $(\mathrm{CFI}=0.935)$ and the Tucker-Lewis Index $(\mathrm{TLI}=0.914)$ indicated that the model was a good fit [52]. Cronbach's alpha reliabilities of all factors were within the traditionally acceptable range [53] of above 0.70 . These values led to the conclusion that the four-factor model was acceptable. Table III summarises each factor's measuring items and Cronbach's alpha reliability values.

The discussion in [13], which found that items related to extrinsic motivation "reflect that executives were more likely to move to cloud-based services when they believed doing so would allow them to better cope with a rapidly changing business environment;" items related to intrinsic motivation, "reflect executives were more likely to move to cloud computing when they perceived that it would strengthen the company, assisting them to gain a competitive advantage in implementing their business strategy; " items related to perceived risks reflect executives' perception of risk, and if they perceive "there is less risk associated with using cloud computing instead of owned resources, they are more likely to switch to cloud-based systems;" and finally, items related to resource constraint "indicate the degree to which executives saw cloud computing as an inexpensive and supplementary solution to acquiring and managing IT resources."

TABLE III

FACTORS WITH MEASURING ITEMS IN THE FOUR-FACTOR MODEL

\begin{tabular}{|c|c|c|c|}
\hline \multirow[b]{2}{*}{ Factor } & \multirow[b]{2}{*}{ Item Code } & \multicolumn{2}{|c|}{ Cronbach's Alpha } \\
\hline & & $\begin{array}{c}\text { Manufacturing } \\
\text { Sector }\end{array}$ & Service Sector \\
\hline $\begin{array}{l}\text { Extrinsic } \\
\text { Motivation }\end{array}$ & $\begin{array}{l}\text { D3, D24, } \\
\text { D27, D28, } \\
\text { D29 }\end{array}$ & 0.929 & 0.925 \\
\hline Intrinsic Motivation & D7, D20, D23 & 0.842 & 0.816 \\
\hline Perceived Risks & $\begin{array}{l}\text { D15, D16, } \\
\text { D18 }\end{array}$ & 0.903 & 0.846 \\
\hline Resource Constraint & D10, D12 & 0.862 & 0.829 \\
\hline
\end{tabular}

The first construct, Extrinsic Motivation, was measured using five items as shown in Table II (Items D3, D24, D27, D28, D29). The second construct, Intrinsic Motivation, was measured by three items (D7, D20, D23). The third construct, Perceived Risks, was measured with Items D15, D16, D18. Finally, the fourth construct, Resource Constraint, was measured by items D10, D12. These items seem to indicate the degree to which executives saw cloud computing as an inexpensive and supplementary solution to acquiring and managing IT resources.

The remaining 16 of the 29 items measured not shown in Table II are as follows: D1 Cost differential; D2 Improving business focus by keeping a leaner business model; D4 Accelerated reengineering benefits; D5 Financial risks shared with cloud computing vendor; D6 Shortage of information technology professionals; D8 Redirection of resources; D9 Increased availability of capital funds; D11 Management of problematic and complex IT functions; D13 Improving customer satisfaction; D14 Misuse of shared organisation's knowledge by vendors against company's interest; D17 Relationship management with suppliers, including reliability and availability; D19 Risk of portability and interoperability; D21 Increasing IT innovation, moving at the speed of change, and time to market; D22 Compliance concerns and legal issues; D25 Ease of use; and D26 Limited customized solution (highly standardised utility like services).

\section{Stage 3. Part B. Decision Tree}

Step 3 Part B explored data clusters/classifications using a principal component analysis and decision trees to identify clusters/classifications and to assess the feasibility of usage of various models, which could be used for further analysis (now and in future). For statistical/analytical techniques, we used the $\mathrm{R}$ programming language on various models that were built on the subsets of: the components; type of industrial sectors, i.e., manufacturing and services; and firm sizes.

Contrary to linear or polynomial regression that creates global models (the predictive formula is supposed to hold in the entire data space), a decision tree effectively creates a different 


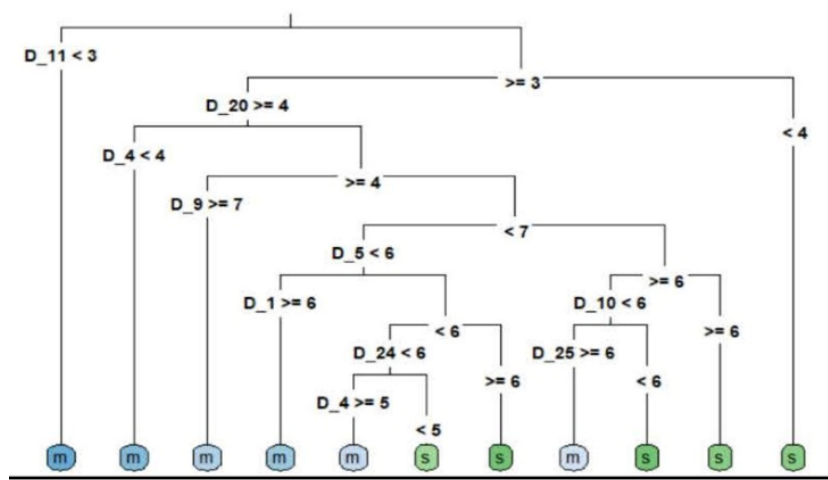

Variables used in tree construction: D11, D19, D9, D,16, D5, D1, D24, D8, D4, D10, D29, D14, D27, D6. Number of terminal nodes: 19 Residual mean deviance: $0.7864=101.5 / 129$

Misclassification error rate: $0.1622=24 / 148$

Fig.1. Decision Tree for Manufacturing and Services Sectors.

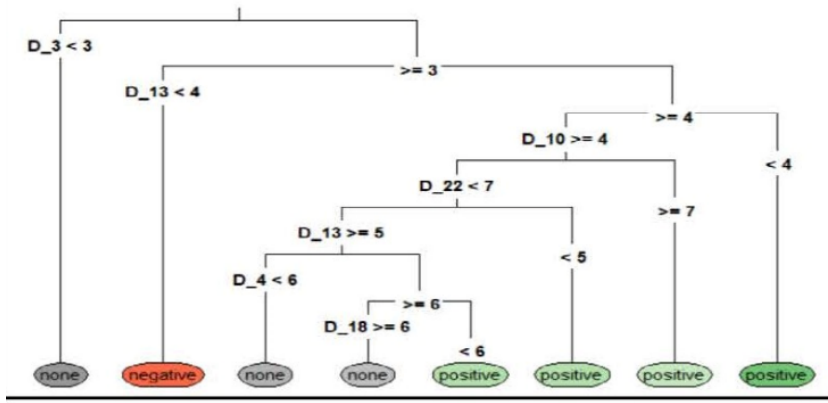

Variables used in tree construction: D13, D3, D18, D22, D1,D26, D2, D23, D16, D25, D6, D21, D20, D14. Number of terminal nodes: 16 Residual mean deviance: $1.045=90.89 / 87$

Misclassification error rate: $0.2136=22 / 103$

Fig. 2. Decision Tree for growth of allocation in budget for cloud computing Firm size classified as: small, medium and large.

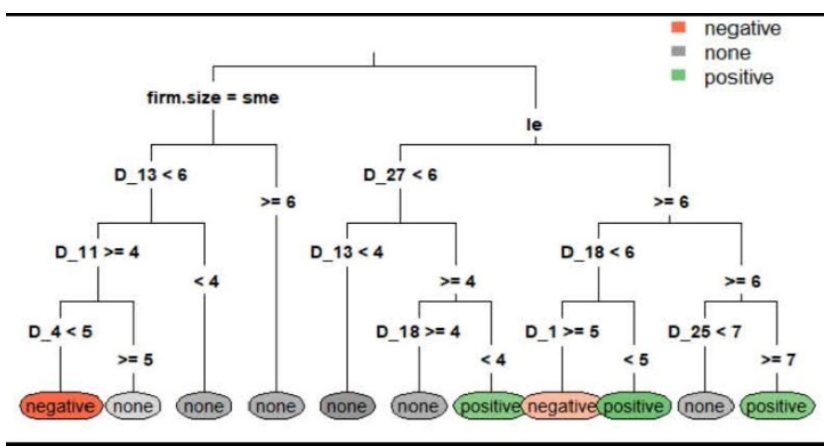

Variables used in tree construction: firm size, D13, D5, D18, D22, D29, D12, D28, D1, D11, D8, D16. Number of terminal nodes: 18 Residual mean deviance: $1.277=166 / 130$

Misclassification error rate: $0.3108=46 / 148$

Fig. 3. Decision Tree classification for growth of allocation in budget.

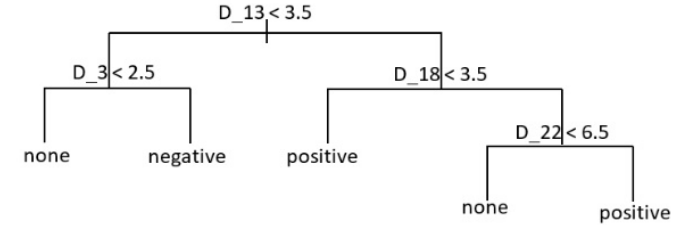

\# Classification tree:Variable actually used in tree construction: \#\# "D 13" "D 3" "D 18" "D 22"

$.68=164.6 / 98$

\#\# Misclassification error rate: $0.3495=36 / 103$

\# Point prediction (the probability output to categorical output) gives the predicted clas \#\# prediction.pruned negative none positive

\#\# negative $\quad 2 \quad 2$

\#\# positive $\begin{array}{cccc}3 & 6 & 5\end{array}$

Fig.4. cv.model.pruned<-prune.misclass(tree.model, best=best.size)-summary (cv.model.pruned).

TABLE IV

The Statistical Significance of the Full Model

\begin{tabular}{|l|c|c|c|c|}
\hline Coefficients & Estimate & Std. Error & $\boldsymbol{t}$-value & $\operatorname{Pr}(>|\mathbf{t}|)$ \\
\hline (Intercept) & 12.558 & 2.110 & 5.952 & $1.98 \mathrm{e}^{-08 * * *}$ \\
\hline cloud.old & 0.813 & 0.041 & 19.723 & $<2 \mathrm{e}^{-16 * * *}$ \\
\hline Industry (service) & -0.734 & 1.622 & -0.452 & 0.6517 \\
\hline firm.size (sme) & -4.079 & 1.697 & -2.403 & $0.0175 *$ \\
\hline cloud.pca1 & 0.471 & 0.198 & 2.375 & $0.0189 *$ \\
\hline cloud.pca2 & 1.443 & 0.698 & 2.068 & $0.0404 *$ \\
\hline
\end{tabular}

Service Sector Percentage of IT Budget Allocation

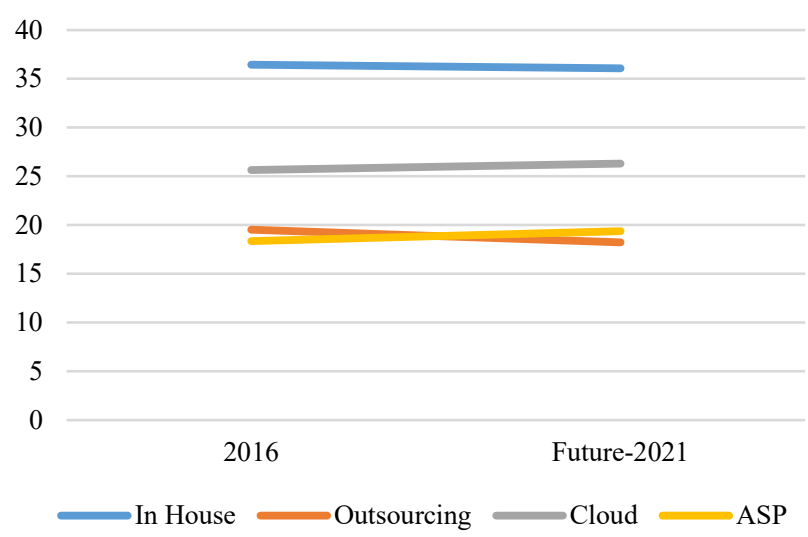

Fig. 5. Current and projected change in the allocation of IT budget for various services - Service Sector.

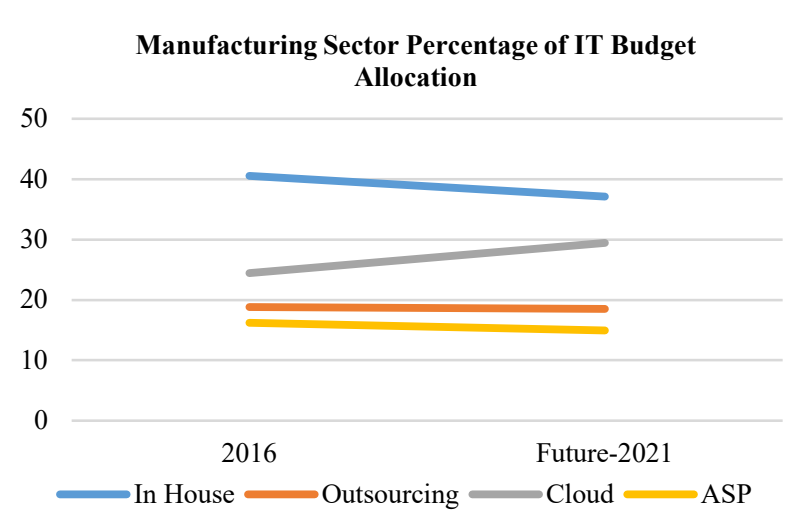

Fig. 6. Current and projected change in the allocation of IT budget for various services - Manufacturing Sector. 
model on each part of the data. "Leaves of a decision tree are class names, other nodes represent attribute-based tests with a branch for each possible outcome. In order to classify an object, we start at the root of the tree, evaluate the test, and take the branch appropriate to the outcome. The process continues until a leaf is encountered; at which time the object is asserted to belong to" [54]. We can prune the tree to prevent overfitting, and we can choose how many leaves we want the tree to have and create the best tree with that size. For classification trees we can also use argument method="misclass" so that the pruning measure should be the number of misclassifications.

TABLE V

Change In IT Budget Allocation

\begin{tabular}{|c|c|c|c|c|c|c|c|c|c|c|c|}
\hline & $N$ & Min & Max & Mean & $\begin{array}{c}\text { Std. } \\
\text { Error }\end{array}$ & Std. Dev & Variance & $\begin{array}{c}\text { Skew- } \\
\text { ness }\end{array}$ & $\begin{array}{c}\text { Std. } \\
\text { Error }\end{array}$ & $\begin{array}{c}\text { Kurto- } \\
\text { sis }\end{array}$ & $\begin{array}{c}\text { Std. } \\
\text { Error }\end{array}$ \\
\hline \multicolumn{12}{|l|}{ Manufacturing Sector } \\
\hline C1_1 InHouse 2016 & 71 & 0 & 100 & 40.54 & & 26.045 & 678.338 & 0.598 & 0.285 & -0.501 & 0.563 \\
\hline C2_1 InHouse 2021 plan & 71 & 0 & 100 & 37.11 & & 25.209 & 635.473 & 0.891 & 0.285 & 0.112 & 0.563 \\
\hline Change in InHouse & 71 & -60 & 50 & -3.42 & & 12.849 & 165.105 & -0.507 & 0.285 & 8.342 & 0.563 \\
\hline C1_2 Outsourcing 2016 & 71 & 0 & 80 & 18.82 & & 16.626 & 276.437 & 1.224 & 0.285 & 2.662 & 0.563 \\
\hline C2_2 Outsourcing 2021 plan & 71 & 0 & 80 & 18.51 & & 16.199 & 262.396 & 0.984 & 0.285 & 1.961 & 0.563 \\
\hline Change in Outsourcing & 71 & -25 & 20 & -0.31 & & 6.863 & 47.103 & -0.873 & 0.285 & 3.737 & 0.563 \\
\hline C1 3 Cloud Computing 2016 & 71 & 0 & 80 & 24.44 & & 15.642 & 244.678 & 1.023 & 0.285 & 2.636 & 0.563 \\
\hline C2 3 Cloud Computing 2021 plan & 71 & 0 & 100 & 29.44 & & 18.852 & 355.392 & 1.270 & 0.285 & 2.850 & 0.563 \\
\hline Change in Cloud Computing & 71 & -25 & 60 & 5.00 & & 12.677 & 160.714 & 1.780 & 0.285 & 5.456 & 0.563 \\
\hline C1_4 ASP 2016 & 71 & 0 & 50 & 16.21 & & 13.332 & 177.740 & 0.187 & 0.285 & -0.742 & 0.563 \\
\hline C2_4 ASP 2021 plan & 71 & 0 & 50 & 14.94 & & 12.731 & 162.082 & 0.407 & 0.285 & -0.187 & 0.563 \\
\hline Change in ASP & 71 & -40 & 20 & -1.27 & & 7.451 & 55.513 & -1.975 & 0.285 & 10.948 & 0.563 \\
\hline \multicolumn{12}{|l|}{ Service Sector } \\
\hline C1_1 InHouse 2016 & 77 & 5 & 100 & 36.45 & 2.635 & 23.123 & 534.672 & 1.367 & 0.274 & 1.151 & 0.541 \\
\hline C2_1 InHouse 2021 plan & 77 & 0 & 100 & 36.08 & 2.654 & 23.291 & 542.468 & 1.303 & 0.274 & 1.104 & 0.541 \\
\hline Change in In-House & 77 & -30 & 40 & -0.38 & 1.238 & 10.863 & 118.001 & 0.517 & 0.274 & 3.460 & 0.541 \\
\hline C1_2 Outsourcing 2016 & 77 & 0 & 50 & 19.53 & 1.461 & 12.821 & 164.384 & 0.005 & 0.274 & -0.456 & 0.541 \\
\hline C2 2 Outsourcing 2021 plan & 77 & 0 & 50 & 18.23 & 1.407 & 12.350 & 152.524 & -0.272 & 0.274 & -0.752 & 0.541 \\
\hline Change in Outsourcing & 77 & -35 & 35 & -1.30 & 1.164 & 10.214 & 104.317 & -0.256 & 0.274 & 3.856 & 0.541 \\
\hline C1_3 Cloud Computing 2016 & 77 & 0 & 80 & 25.65 & 1.691 & 14.835 & 220.073 & 1.282 & 0.274 & 3.868 & 0.541 \\
\hline C2_3 Cloud Computing 2021 plan & 77 & 0 & 80 & 26.31 & 1.722 & 15.114 & 228.428 & 1.070 & 0.274 & 2.603 & 0.541 \\
\hline Change in Cloud Computing & 77 & $-\mathbf{5 0}$ & 25 & 0.66 & 1.273 & 11.172 & 124.806 & -0.960 & 0.274 & 5.233 & 0.541 \\
\hline C1_4 ASP 2016 & 77 & 0 & 60 & 18.36 & 1.422 & 12.477 & 155.682 & 0.624 & 0.274 & 0.875 & 0.541 \\
\hline C2_4 ASP 2021 plan & 77 & 0 & 60 & 19.38 & 1.427 & 12.519 & 156.738 & 0.248 & 0.274 & 0.311 & 0.541 \\
\hline Change in ASP & 77 & -25 & 50 & 1.01 & 1.126 & 9.878 & 97.566 & 1.556 & 0.274 & 8.008 & 0.541 \\
\hline
\end{tabular}

As shown in Fig. 1, the misclassification rate is 0.1622 $(16.22 \%)$, which seems to be on a higher side to generalize the classification as significant. The misclassification rate in Fig. 2, 0.3108 (31.08\%), and Fig. 3, 0.2136 (21.36\%), seem to be on a higher side to generalize the classification as significant. Using the test data (Fig. 4), from the plot, point prediction, and results to find the best tree, using k-fold, which gives the deviance from each $\mathrm{k}$ (criteria: small is better), the classification tree for the size of organisation (small, medium, and large) reveals that the misclassification rate is $0.3495(34.95 \%)$, which seems to be on a higher side to generalize the classification as significant.

The results from the decision tree were not significant. One of the reasons for insignificant results might be a lower sample size. Considering this aspect of lower sample size, we intended to explore further the usability of these methods for our future studies where we might have a higher sample size. We continued our analysis using the traditional approach, i.e., the development of a regression model for the study.

Stage 3. Part C. Regression Model

In the model (MODEL: cloud.new $\sim$ cloud.old + industry + firm.size + cloud.pca1 + cloud.pca2, data $=$ model1 $)$, the dependent variable is the expected budget allocation for cloud computing (cloud.new); and independent variables include:
Budget allocation for cloud computing (cloud.old), Industry (service vs. manufacturing), Firm revenue (large vs. small and medium), and two principal components ( $67 \%$ variance) from the 29 measured items. This full model is statistically significant with multiple $R^{2}: 0.7741$, Adjusted $R^{2}$ : 0.7661 ; $F$-statistic: 97.3 on 5 and $142 \mathrm{DF}, p$-value: $<2.2 \mathrm{e}^{-16}$ (Significant). The detailed results are shown in Table IV.

Based on the analysis, it can be inferred that future trends (in 2021 ) in the allocation of IT budget in cloud computing have significant association with the present (in 2016) allocation of budget in cloud computing. Furthermore, the future trends (in 2021 ) in the allocation of IT budget in cloud computing has also significant association with the size of the firms.

\section{RESULTS AND DISCUSSION}

The analysis was performed using SPSS Version 23.0, the data/variables were computed separately for the manufacturing and service sectors for ranking of data items/variables, and growth in the trends of allocation of IT budget in cloud computing. Furthermore, the computation was extended to perform a stepwise regression analysis to assess the identified factors (Extrinsic Motivation, Intrinsic Motivation, Perceived Risks, and Resource Constraint) to test the hypotheses. 


\section{A. Trends in the Allocation of IT Budget for Various Services}

Table V shows growth in spending on cloud computing (includes application service providers (ASP), which is considered another form of cloud computing) over five years. In the manufacturing sector, this growth was $3.73 \%$, while growth in the service sector was $1.67 \%$. In outsourcing/offshoring, there was a decline of $0.31 \%$ for the manufacturing sector and $1.30 \%$ for the service sector. Considering ASPs and cloud computing as another form of outsourcing/offshoring, the overall decline (3.42\%) of in-house IT services shifted to IT outsourcing/offshoring; ASPs, and cloud computing over a period of five years in the manufacturing sector and $0.38 \%$ in the service sector.

In terms of IT budget in 2016 , about $40 \%$ was dedicated to in-house, and the rest was allocated to outsourcing/offshoring (18\%), cloud computing (25\%), and ASP (16\%) in the manufacturing sector. Overall, the planned in-house IT services budget for the manufacturing sector declined slightly to about $37 \%$ in 2021 with the increase absorbed in cloud computing $(29 \%)$; while other areas stayed relatively unchanged: outsourcing/offshoring (18\%) and ASP (15\%). The service sector allocation in 2016 was $36 \%$ for in-house development, $19 \%$ for outsourcing/offshoring, $25 \%$ for cloud computing, and $18 \%$ for ASPs. Planned in-house IT services budget in the services sector stayed consistent $(36 \%)$ in 2021 , with minor adjustments in other categories, $26 \%$ for cloud computing; $18 \%$ for outsourcing/offshoring, and $19 \%$ for ASPs.

For the trends in cloud computing budget allocation, the kurtosis were mostly in the range of 5 for both sectors, while the responses were skewed positively to 1.78 for the manufacturing sector and negatively to 0.96 for the service sector. Please refer to the next section for the implications of these trends.

Figures 5 and 6 show the expected change in the usage of IT services. The contribution in each category is approximately equal in percentage ranging from 20 to 40 in both manufacturing and service sectors. The projected changes in IT budget allocation decisions in five years reveal that respondents perceive a marginal decline in the expected in-house services and IT outsourcing/offshoring, and a marginal increase in the usage of cloud services. However, in case of the usage of ASPs, there is a decline in the manufacturing sector, while a marginal increase in the service sector.

\section{B. Regression Analysis fMajor Hypotheses and Contributing \\ Factors to Support the Trends in the Usage of Cloud Computing}

Regression analysis was used to evaluate hypotheses $\mathrm{H} 1-\mathrm{H} 4$ for the four predictors: Extrinsic Motivation, Intrinsic Motivation, Perceived Risks, and Resource Constraint. Tables VI-VII show the analysis for the manufacturing sector and Tables VIII-IX for the service sector to predict the change in percent of budget for cloud computing and the growth in cloud computing.

In the manufacturing sector, hypotheses $\mathrm{H} 1, \mathrm{H} 2, \mathrm{H} 3$, and $\mathrm{H} 4$ were not supported as the model was statistically insignificant for the change in percent of the budget allocation for cloud computing, between 2016 and 2021, with an $R^{2}$ of 0.41 ,
$F$-statistic of 0.714 , and a $p$-value of 0.585 . Coefficient estimates in Table VII show insignificant $p$-values of all four factors.

A statistically significant $(p<0.05)$ F-statistic signifies the model did a good job of predicting the outcome variable and a significant relationship between the predictors and dependent variable. The low value of $R^{2}$ possibly signifies that additional predictors can increase the explanatory power of the model. In manufacturing sector, after eliminating all variables except Extrinsic Motivation, the model is statistically significant for the change in Cloud Computing budget allocation with an $R^{2}$ of $0.216, F$-statistic of 18.955 , and a $p$-value of 0.000 . Coefficient estimates shown in Table VIII also show significant p-values of variable Extrinsic Motivation for Cloud Computing. In case of the manufacturing sector, hypothesis $\mathrm{H} 1$ was supported, while $\mathrm{H} 2, \mathrm{H} 3$, and $\mathrm{H} 4$ were not proven for growth in budget allocation.

In the service sector, the model is statistically significant for growth in percentage of budget allocation for cloud computing, with an $R^{2}$ of $0.064, F$-statistic of 5.133, and a $p$-value of 0.026 . Coefficient estimates shown in Table IX also demonstrate significant $p$-values (0.026) of the variable Intrinsic Motivation for Cloud Computing. Therefore, in case of the service sector, hypothesis $\mathrm{H} 2$ was supported, while H1, H3, and H4 were not supported.

Furthermore, in the service sector, even after eliminating three variables from the analysis, the model is statistically significant for growth in Cloud Computing budget allocation for 2021 with an $R$-Square of $0.125, F$-statistic of 10.703 , and a $p$-value of 0.002 . Coefficient estimates from the regression analysis shown in Table IX also demonstrate significant $\mathrm{p}$ values (0.002) of variable Intrinsic Motivation for Cloud Computing. In the service sector, hypothesis $\mathrm{H} 2$ was supported for the growth in cloud computing budget allocation, while $\mathrm{H}$, $\mathrm{H} 3$, and $\mathrm{H} 4$ were not supported.

\section{Implications of IT Budget Allocation}

This study demonstrated that by 2021 , organisations would be meeting IT needs by investing small amount of IT budget in cloud computing. The small growth in all forms of outsourcing (including cloud computing and ASPs) over a period of five years $(3.42 \%$ for the manufacturing sector and $0.38 \%$ for service sector) corresponds to reduction in in-house IT services budget.

About $40 \%$ of the IT budget dedicated to cloud computing and ASP in the manufacturing sector in 2016 and about $44 \%$ in the service sector along with the planned increase (44\%) in the next five years for cloud computing of the IT budget in the manufacturing sector and $46 \%$ in the service sector imply that organisations are satisfied with this option without compromising other alternative avenues such as IT outsourcing/ offshoring and in-house development.

The allocation of IT budget has an important implication for the recruitment of IT professionals in specific areas and subsequently the need to develop curricula at educational institutions to respond to the labour market. For example, to develop applications in the manufacturing sector where 
approximately $44 \%$ of IT budget is allocated to the combination of IT cloud computing and IT application service provider, relatively few IT professionals having skills in business processes are needed for the implementation of readily supported IT applications.

TABLE VI

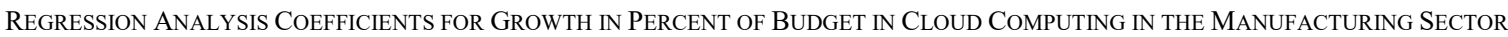

\begin{tabular}{|c|c|c|c|c|c|c|c|c|c|c|c|}
\hline & & & & & Coeffi & $n^{a} s^{a}$ & & & & & \\
\hline & del & $\begin{array}{r}\text { Unst } \\
\text { Ce }\end{array}$ & $\begin{array}{l}\text { ardized } \\
\text { cients }\end{array}$ & $\begin{array}{c}\text { Standardized } \\
\text { Coefficients }\end{array}$ & $t$ & Sig & & $\begin{array}{c}\text { Sum of } \\
\text { Squares }\end{array}$ & $d f$ & $F$ & Sig \\
\hline & & $\boldsymbol{B}$ & Std. Error & Beta & & & & & & & \\
\hline 1 & (Constant) & 0.960 & 5.470 & & 0.176 & 0.861 & Regression & 420.31 & 4 & 0.714 & 0.585 \\
\hline & $\begin{array}{l}\text { Extrinsic } \\
\text { Motivation }\end{array}$ & 3.309 & 2.277 & 0.390 & 1.453 & 0.151 & Residual & 9715.6 & 66 & & \\
\hline & $\begin{array}{l}\text { Intrinsic } \\
\text { Motivation }\end{array}$ & -0.812 & 2.025 & -0.094 & -0.401 & 0.690 & Total & 10135 & 70 & & \\
\hline & Perceived Risks & -0.529 & 1.547 & -0.070 & -0.342 & 0.734 & & & & & \\
\hline & $\begin{array}{l}\text { Resource } \\
\text { Constraint }\end{array}$ & -1.532 & 1.358 & -0.205 & -1.128 & 0.263 & & & & & \\
\hline
\end{tabular}

TABLE VII

REgRESSION ANALysis COEFFICIENTS FOR AsSOCIATION BETWEEN THE MANUFACTURING SECTOR GROWTH IN ClOUd COMPUTING BudGET ALLOCATION IN YEAR 2021

\begin{tabular}{|c|c|c|c|c|c|c|c|c|c|c|c|}
\hline & & \multicolumn{10}{|c|}{ Coefficients $^{\mathrm{a}}$} \\
\hline \multirow{2}{*}{\multicolumn{2}{|c|}{ Model }} & \multicolumn{2}{|c|}{$\begin{array}{c}\text { Unstandardized } \\
\text { Coefficients }\end{array}$} & \multirow{2}{*}{$\begin{array}{c}\begin{array}{c}\text { Standardized } \\
\text { Coefficients }\end{array} \\
\text { Beta }\end{array}$} & \multirow[t]{2}{*}{$t$} & \multirow[t]{2}{*}{ Sig. } & & \multirow[t]{2}{*}{$\begin{array}{c}\text { Sum of } \\
\text { Squares }\end{array}$} & \multirow[t]{2}{*}{$d f$} & \multirow[t]{2}{*}{$\boldsymbol{F}$} & \multirow[t]{2}{*}{ Sig } \\
\hline & & B & Std. Error & & & & & & & & \\
\hline \multirow[t]{3}{*}{1} & (Constant) & 9.929 & 8.238 & & 1.205 & 0.232 & Regression & 7070.5 & 1 & 18.96 & 0.000 \\
\hline & $\begin{array}{l}\text { Extrinsic } \\
\text { Motivation }\end{array}$ & 7.094 & 1.629 & 0.464 & 4.354 & 0.000 & Residual & 25738.2 & 69 & & \\
\hline & & & & & & & Total & 32808.7 & 70 & & \\
\hline \multicolumn{12}{|c|}{ Dependent Variable: MCloud 2021} \\
\hline
\end{tabular}

TABLE VIII

Regression Analysis Coefficients for Change in Percent of Budget in Cloud Computing IN the SERVice SeCtor

\begin{tabular}{|c|c|c|c|c|c|c|c|c|c|c|c|}
\hline & & \multicolumn{10}{|c|}{ Coefficients $^{\mathrm{a}}$} \\
\hline \multirow{2}{*}{\multicolumn{2}{|c|}{ Model }} & \multicolumn{2}{|c|}{$\begin{array}{c}\text { Unstandardized } \\
\text { Coefficients }\end{array}$} & \multirow{2}{*}{$\begin{array}{c}\begin{array}{c}\text { Standardized } \\
\text { Coefficients }\end{array} \\
\text { Beta }\end{array}$} & \multirow[t]{2}{*}{$t$} & \multirow[t]{2}{*}{ Sig. } & & \multirow[t]{2}{*}{$\begin{array}{c}\text { Sum of } \\
\text { Squares }\end{array}$} & \multirow[t]{2}{*}{$d f$} & \multirow[t]{2}{*}{$\boldsymbol{F}$} & \multirow[t]{2}{*}{ Sig } \\
\hline & & $B$ & Std. Error & & & & & & & & \\
\hline \multirow{3}{*}{1} & (Constant) & -6.926 & 3.926 & & -1.764 & 0.082 & Regression & 396.027 & 1 & 5.13 & 0.026 \\
\hline & $\begin{array}{l}\text { Intrinsic } \\
\text { Motivation }\end{array}$ & 1.746 & 0.771 & 0.253 & 2.266 & 0.026 & Residual & 5786.86 & 75 & & \\
\hline & & & & & & & Total & 6182.88 & 76 & & \\
\hline
\end{tabular}

TABLE IX

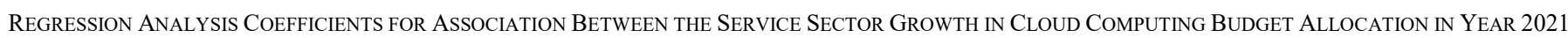

\begin{tabular}{|c|c|c|c|c|c|c|c|c|c|c|c|}
\hline & & \multicolumn{10}{|c|}{ Coefficients $^{\mathrm{a}}$} \\
\hline \multirow{2}{*}{\multicolumn{2}{|c|}{ Model }} & \multicolumn{2}{|c|}{$\begin{array}{c}\text { Unstandardized } \\
\text { Coefficients }\end{array}$} & \multirow{2}{*}{$\begin{array}{c}\begin{array}{c}\text { Standardized } \\
\text { Coefficients }\end{array} \\
\text { Beta } \\
\end{array}$} & \multirow[t]{2}{*}{$t$} & \multirow[t]{2}{*}{ Sig. } & & \multirow[t]{2}{*}{$\begin{array}{c}\text { Sum of } \\
\text { Squares }\end{array}$} & \multirow[t]{2}{*}{$d f$} & \multirow[t]{2}{*}{$\boldsymbol{F}$} & \multirow[t]{2}{*}{ Sig } \\
\hline & & $\boldsymbol{B}$ & Std. Error & & & & & & & & \\
\hline \multirow{3}{*}{1} & (Constant) & 21.50 & 7.647 & & 2.812 & 0.006 & Regression & 3132.2 & 1 & 10.70 & 0.002 \\
\hline & $\begin{array}{l}\text { Intrinsic } \\
\text { Motivation }\end{array}$ & 4.910 & 1.501 & 0.353 & 3.272 & 0.002 & Residual & 21948.4 & 75 & & \\
\hline & & & & & & & Total & 25080.5 & 76 & & \\
\hline \multicolumn{12}{|c|}{ Dependent Variable: SCloud 2021} \\
\hline \multicolumn{12}{|c|}{ Predictors: (Constant), Intrinsic Motivation } \\
\hline
\end{tabular}


For the remaining, where $57 \%$ of IT budget is allocated in the manufacturing sector, the IT department may either obtain in-house or procure from outsourcers. If they were to obtain inhouse, they would need to recruit and/or maintain a team of IT professionals.

Finally, the study also showed that organisations would rely on both inside and outside sources to fulfil their IT needs - i.e., in-house IT department, outsourcers, application service providers, and cloud computing. The dominance of outside sources in turn demands the IT department to collaborate with different vendors. Therefore, vendor development as well as management is expected to be a vital function and thus must be incorporated in training the future generations of IT professionals.

\section{CONCLUSION}

The main objective of this study was to gain a better understanding of the current and future trends in the usage of IT cloud computing and its implications for organisations in the manufacturing and service sectors in the United States. This study found extrinsic motivation to be an important factor in the manufacturing sector's decision to increase the IT budget allocation for cloud computing as executives indicated it would allow them to better cope with the rapidly changing business environment; and also found intrinsic motivation to be an important factor in the service sector's decision, as executives indicated that cloud-based services would strengthen their company, assisting them to gain a competitive advantage in implementing their business strategy.

There are several opportunities for future research from this study. First, further refinement of the measuring items is warranted; while the current survey items helped advance this exploratory research, the number of factors that are crossloaded is a concern. Second, the results suggest that it might be useful to develop a more comprehensive model; additional factors such as organisational maturity and IS sophistication might be considered. Third, a longitudinal study (if possible) definitely improves the robustness of the result.

\section{REFERENCES}

[1] D. Knarr, "NVidia Graphics Card Specification Chart," Studio 1 Productions, 2701 2020. [Online]. Available: studiol productions.com/Articles/NVidia-GPU-Chart.htm.

[2] L. Columbus, Forbes, 7 April 2019. [Online]. Available: forbes.com/sites/louiscolumbus/2019/04/07/public-cloud-soaring-to331b-by-2022-according-to-gartner/\#4b8e9e835739.

[3] S. Moore, "Gartner Says 28 Percent of Spending in Key IT Segments Will Shift to the Cloud by 2022," Gartner, 1809 2018. [Online]. Available: gartner.com/en/newsroom/press-releases/2018-09-18-gartner-says-28percent-of-spending-in-key-IT-segments-will-shift-to-the-cloud-by2022.

[4] K. Costello, "Gartner Forecasts Worldwide Public Cloud Revenue to Grow 17.5 Percent in 2019," Gartner, 204 2019. [Online]. Available: gartner.com/en/newsroom/press-releases/2019-04-02-gartner-forecastsworldwide-public-cloud-revenue-to-g.

[5] M. Carroll, A. v. d. Merwe and P. Kotzé, "Secure cloud computing: Benefits, risks and controls," Computer Science, 2011 Information Security for South Africa, Johannesburg, pp. 1-9, 2011. https://doi.org/10.1109/ISSA.2011.6027519
[6] N. Statt, "US Interior Department is grounding its drone fleet due to risks of Chinese spying," The Verge, 3010 2019. [Online]. Available: theverge.com/2019/10/30/20940921/us-interior-department-dronegrounding-china-spying-cybersecurity-risk.

[7] L. C. Baldor, "Pentagon restricts use of fitness trackers, other devices," Associated Press, 0608 2018. [Online]. Available: apnews.com/d29c724e1d72460fbf7c2e999992d258/Pentagon-restrictsuse-of-fitness-trackers,-other-devices.

[8] D. Volz, "Trump signs into law U.S. government ban on Kaspersky Lab software," Reuters, $12 \quad 12 \quad 2017 . \quad$ [Online]. Available: reuters.com/article/us-usa-cyber-kaspersky/trump-signs-into-law-u-sgovernment-ban-on-kaspersky-lab-software-idUSKBN1E62V4.

[9] P. M. a. T. Grance, "The NIST Definition of Cloud Computing," National Institute of Standards and Technology, September 2011. [Online]. Available: faculty.winthrop.edu/domanm/csci411/Handouts/NIST.pdf.

[10] V. Vladimirskiy, "10 Popular Software as a Service (SaaS) Examples," Nerdio, 2010 2016. [Online]. Available: https://getnerdio.com/academy/10-popular-software-service-examples/.

[11] Tech Target, "Platform as a Service (PaaS)," TechTarget.com, November 2019. [Online]. Available: searchcloudcomputing.techtarget.com/definition/Platform-as-a-ServicePaaS

[12] S. Watts and M. Raza, "SaaS vs PaaS vs IaaS: What's The Difference and How To Choose," BMC Software, Inc, 1506 2019. [Online]. Available: bmc.com/blogs/saas-vs-paas-vs-iaas-whats-the-difference-and-how-tochoose/.

[13] V. K. Agrawal, V. K. Agrawal, A. R. Taylor and N. N. Chau, "An Exploratory Study of Factors Driving Decision Makers to Adopt Cloud Computing," Information Technology and Management Science, Vol. 22, pp. 37-46, 2019. https://doi.org/10.7250/itms-2019-0006

[14] E. Kaynak, E. Tatoglu and V. Kula, "An analysis of the factors affecting the adoption of electronic commerce by SMEs: Evidence from an emerging market," International Marketing Review, vol. 22, no. 6, 2005. https://doi.org/10.1108/02651330510630258

[15] A. Caldarelli, L. Ferri and M. Maffei, "Expected benefits and perceived risks of cloud computing: an investigation within an Italian setting," Technology Analysis \& Strategic Management, vol. 29, no. 2, pp. 167180, 2017. https://doi.org/10.1080/09537325.2016.1210786

[16] C. Y. Yeun and S. A. Almulla, "Cloud computing security management," in Second International Conference on Engineering System Management and Applications, 2010.

[17] B. Hayes, "Cloud Computing," Communications of the ACM, vol. 51, pp. 9-11, 2008. https://doi.org/10.1145/1364782.1364786

[18] Distributed Management Task Force, Inc. (DMTF), "Open Virtualization Format Specification," Distributed Management Task Force, Inc. (DMTF), 2013. [Online]. Available: dmtf.org/sites/default/files/standards/documents/DSP0243 2.1.0.pdf.

[19] N. Loutas, E. Kamateri, F. Bosi and K. Tarabanis, "Cloud Computing Interoperability: The State of Play," in 2011 IEEE Third International Conference on Cloud Computing Technology and Science, pp. 752-757. https://doi.org/10.1109/CloudCom.2011.116

[20] Kynetix Technology Group, "Cloud Computing: A Strategy Guide for Board Level Executives," 2009. [Online]. Available: docplayer.net/amp/6003889-Cloud-computing-a-strategy-guide-forboard-level-executives.html.

[21] S. J. Andriole, "Viewpoint: Ready Technology," Communications of the $A C M$, vol. 57, pp. 40-42, 2014. https://doi.org/10.1145/2556941

[22] E. M. Rogers, Diffusion of Innovations. New York: The Free Press, 2010.

[23] L. Kappelman, E. McLean, V. Johnson, R. Torres, Q. Nguyen, C. Maurer and M. and Snyder, "The 2016 SIM IT Issues and Trends Study," MIS Quarterly Executive, vol. 16, no. 1, p. 6, 2017.

[24] Dutta, G. C. A. Peng and A. Choudhary, "Risks in Enterprise Cloud Computing: The Perspective of it Experts," Journal of Computer Information Systems, vol. 53, no. 4, 2013. https://doi.org/10.1080/08874417.2013.11645649

[25] Y. S. Patel, N. Mehrotra and S. Soner, "Green Cloud Computing: A Review on Green IT Areas for Cloud Computing Environment," in International Conference on Futuristic trend in Computational Analysis and Knowledge Management, Noida, India, 2015. https://doi.org/10.1109/ABLAZE.2015.7155006 
[26] K. Dahbur, B. Mohammad and A. B. Tarakji, "A survey of risks, threats and vulnerabilities in cloud computing," in Proceedings of the 2011 International Conference on Intelligent Semantic Web-Services and Applications, 2011. https://doi.org/10.1145/1980822.1980834

[27] United States Government, "Health Insurance Portability \& Accountability Act," 2019. [Online]. Available: dhcs.ca.gov/formsandpubs/laws/hipaa/Pages/1.00WhatisHIPAA.aspx.

[28] Intersoft Consulting, "General Data Protection Regulation GDPR," [Online]. Available: gdpr-info.eu/.

[29] T. Mather, S. Kumaraswamy and S. Latif, Cloud Security and Privacy: An Enterprise Perspective on Risks and Compliance. Oreilly, 2009.

[30] S. Gallagher, "Baltimore's bill for ransomware: Over \$18 million, so far," Arstechnica, 0506 2019. [Online].

Available: arstechnica.com/information-technology/2019/06/baltimoresbill-for-ransomware-over-18-million-so-far/.

[31] J. Miller, "Were warnings about city government cybersecurity missed?," WBALTV, May 2019. [Online]. Available: wbaltv.com/article/cybersecurity-warnings-baltimore-government/27482509\#.

[32] Z. Zhang, C. Wu and D. W. Cheung, "A Survey on Cloud Interoperability: Taxonomies, Standards, and Practice," ACM SIGMETRICS Performance Evaluation Review, vol. 40, no. 4, 2013. https://doi.org/10.1145/2479942.2479945

[33] N. G. Carr, “IT Doesn't Matter," Harvard Business Review, May 2003.

[34] N. Carr, The Big Switch. New York: W. W. Norton \& Company, 2008.

[35] Y. L. Antonucci and J. J. Tucker III, "IT Outsourcing: Current Trends, Benefits, and Risks," Information Strategy: The Executive's Journal, vol. 14, no. 2, pp. 16-26, 1998. https://doi.org/10.1080/07438613.1998.10744580

[36] S. J. Andriole, "Who Owns IT?," Communications of the ACM, vol. 58, pp. 50-57, 2015. https://doi.org/10.1145/2660765

[37] Jared Spataro, Corporate Vice President for Microsoft 365, "Update \#2 on Microsoft cloud services continuity,” 2903 2020. [Online]. Available: microsoft.com/en-us/microsoft-365/blog/2020/03/29/update-2-microsoftcloud-services-continuity/.

[38] I. Son, D. Lee, J.-N. Lee and Y. B. Chang, "Market perception on cloud computing initiatives in organizations: An extended resource-based view," Information \& Management, vol. 51, no. 6, pp. 653-669, 2014. https://doi.org/10.1016/j.im.2014.05.006

[39] M. Sena and J. Sena, "Make or Buy: A comparative assessment of organizations that develop software internally versus those that purchase software," in Conference on Information Systems Applied Research, Nashville, 2010.

[40] N. Sultan, "Cloud computing: A democratizing force?," International Journal of Information Management, vol. 33, no. 5, pp. 810-815, 2013. https://doi.org/10.1016/j.ijinfomgt.2013.05.010

[41] D. A. Dillman, Mail and Telephone Surveys: The Total Design Method. John Wiley and Sons, New York, 1978.

[42] D. A. Dillman, Mail and internet surveys: The tailored design method. John Wiley and Sons, New York, 2000.

[43] A. B. Blankenship, G. Breen and A. Dutka, "State of the Art Marketing Research," American Marketing Association, 1998.

[44] H. F. Kaiser, "A second-generation little jiffy," Psychometrika vol. 35, pp. 401-415, 1970. https://doi.org/10.1007/BF02291817

[45] H. F. Kaiser and J. Rice, "Little Jiffy, Mark IV," Educational and Psychological Measurement, pp. 111-117, 1974. https://doi.org/10.1177/001316447403400115

[46] J.-O. Kim and C. W. Mueller, Factor Analysis: Statistical Methods and Practical Issues. Sage Publications Inc., 1978. https://doi.org/10.4135/9781412984256

[47] M. Bartlett, "Tests of significance in factor analysis," British Journal of Psychology, vol. III, part II, pp. 77-85, June 1950. https://doi.org/10.1111/i.2044-8317.1950.tb00285.x

[48] J. F. Hair, R. L. Tatham, R. E. Anderson and W. C. Black, Multivariate Data Analysis. Englewood Cliffs, Prentice-Hall, 1995

[49] B. G. Tabachnick and L. S. Fidell, Using Multivariate Statistics $\left(^{\text {th }}\right.$ Edition). Pearson, 2007.

[50] J. Joseph F. Hair, W. C. Black, B. J. Babina and R. E. Anderson, Multivariate Data Analysis A Global Perspective. Boston: Pearson, 2014.
[51] P. Mahatanankoon, H. J. Wen and B. Lim, "Consumer-based mcommerce: exploring consumer perception of mobile applications," Computer Standards \& Interfaces, vol. 27, no. 4, pp. 347-357, 42005. https://doi.org/10.1016/j.csi.2004.10.003

[52] D. A. Kenny, B. Kaniskan and D. B. McCoach, "The Performance of RMSEA in Models With Small Degrees of Freedom," Sociological Methods \& Research , 2014. https://doi.org/10.1177/0049124114543236

[53] J. C. Nunnally, Introduction to psychological measurement. McGraw-Hill Inc., 1970.

[54] J. Quinlan, "Induction of Decision Trees," Machine Learning, vol. 1, pp. 81-106, March 1986. https://doi.org/10.1007/BF00116251

[55] A. Mathur, "Impact of User Characteristics on Attitudes Towards Automatic Mobile Application Updates," in USNIX Conference, 2017.

[56] V. Venkatesh and F. D. Davis, "A model of the antecedents of perceived ease of use: Development and test," Decision Sciences, pp. 451-481, 1996. https://doi.org/10.1111/j.1540-5915.1996.tb01822.x

[57] E. Smith and M. Shirer, "Worldwide Public Cloud Services Spending Forecast to Reach $\$ 210$ Billion This Year," 2802 2018. [Online]. Available: idc.com/getdoc.jsp?containerId=prUS44891519.

Vipin K. Agrawal received his $\mathrm{PhD}$ in Finance from the University of Texas at Austin. He is currently an Associate Professor in Practice at the University of Texas at San Antonio (UTSA). His research has been published in journals such as The Quarterly Review of Economics and Finance, Production and Operations Management, and Decision Sciences Journal of Innovative Education. In addition, he has also published a peer-review monograph titled "Corporate Policies in a World with Information Asymmetry."

E-Mail: Vipin.Agrawal@utsa.edu

ORCID iD: https://orcid.org/0000-0001-6364-2631

Vijay K. Agrawal is a Professor of Business Intelligence at the College of Business and Technology (CBT) at the University of Nebraska at Kearney (UNK). His areas of interest are business intelligence, operations management, and accounting. He received his PhD from Jamia Millia Islamia (University of Millia Islamia), New Delhi, India. He worked for 20 years in various industries and approximately more than 20 years in academia. He has published in Production and Operations Management, Decision Sciences Journal of Innovative Education, National Social Science Journal, Global Journal of Flexible Systems Management, Encyclopaedia of Operations Research and Management Science, Information Technology and Management Science, and others.

E-Mail: agrawalvk@unk.edu

ORCID iD: https://orcid.org/0000-0002-7012-1321

Ngan N. Chau is an Associate Professor of Marketing in CBT at UNK. Her areas of interest are supply chain management, durable goods marketing, and digital marketing channels. She received her $\mathrm{PhD}$ from the University of Central Florida. Her research has been published in journals such as Production and Operations Management, Journal of Internet Commerce, and Journal of Marketing Channels.

E-Mail: chaunn@unk.edu

ORCID iD: https://orcid.org/0000-0002-9770-6418

Mathew Miller is an Associate Professor of Computer Science in CBT at UNK. $\mathrm{He}$ received his $\mathrm{PhD}$ in Computer Science from Kansas State University. Dr Miller serves as an expert witness on numerous Federal Cases, where he reverse engineered the NIT code provided by the government. His expert declarations have been used by the ACLU in their "Challenging Government Hacking in Criminal Cases" guide for attorneys.

E-Mail: millermj@unk.edu

Sherri Harms is a Professor of Computer Science in CBT at UNK. In addition to several years of industry experience in software development, she has been in academia for more than twenty years. Her research areas include computer science education and temporal data mining. She has numerous peer reviewed journal and conference publications, with research funded by NSF, USDA, Google, and state agencies. She received her $\mathrm{PhD}$ from the University of Missouri.

E-Mail: harmssk@unk.edu

ORCID iD: https://orcid.org/0000-0002-3653-2928 